\title{
EVALUATING A RANGING PROTOCOL FOR 3D IMAGING SYSTEMS
}

\author{
Geraldine S Cheok, Kamel S. Saidi, Alan M. Lytle \\ National Institute of Standards and Technology \\ 100 Bureau Drive \\ Gaithersburg, MD 20899-8611 \\ \{cheok, kamel.saidi, alan.lytle\}@nist.gov
}

\begin{abstract}
In 2006, the ASTM E57 committee was established to develop standards for 3D imaging systems. A 3D imaging system is a non-contact instrument that is used to measure the range and bearing to and/or the 3D coordinates of points on an object or within a region of interest. A draft protocol to evaluate the range error in these systems was proposed. Two rounds of tests were conducted in 2007 to evaluate the ranging protocol. The evaluation of the protocol revealed that it was impractical to test the proposed 60 combinations of factors due to the length of time required. However, sixteen combinations using planar targets can be completed in one day. Measuring the "true" distance from the 3D imaging system to the targets was performed using a laser tracker during the first round of tests and a total station during the second round. The procedures for these measurements as well as the interaction between the main factors need further consideration.
\end{abstract}

\section{KEYWORDS}

3D Imaging Systems, ASTM E57, Laser Scanning, Ranging, Standards, Test Protocol.

\section{INTRODUCTION}

In June 2006, the ASTM Committee E57 on 3D imaging systems was established. A 3D imaging system is a non-contact instrument that is used to measure the range and bearing to and/or the $3 \mathrm{D}$ coordinates of points on an object or within a region of interest. The specific type of systems E57 is initially focusing on are laser-based, timeof-flight systems, which are also often referred to as laser scanners or LADARs (laser detection and ranging).

A subcommittee, E57.02 - Test Methods, was formed to develop test methods to evaluate these systems. A draft protocol to evaluate the range error was proposed. This draft ranging protocol was developed based on input from a series of workshops on 3D imaging systems held at the National Institute of Standards and Technology between 2003 and 2006. Some initial concerns with the protocol included the overall time required to complete the testing, support equipment requirements, and data analysis methods. In order to better understand the challenges of conducting the range testing as proposed, an evaluation of the protocol was necessary. This paper briefly describes the ranging protocol and the preliminary findings of challenges encountered.

\section{RANGING PROTOCOL}

The draft ranging protocol is described in detail in [1]. In brief, the protocol seeks to evaluate range error as a function of four factors - distance, target reflectivity, angle of incidence (AOI), and azimuth angle. At the NIST workshops, these factors were identified as being the major sources of range error.

The draft ranging protocol proposed to vary the above factors as follows: 
Distance (from instrument to target) - 5 levels, $D_{1}, \ldots, D_{5}$ :

- smaller of $\left(10 \% R \leq D_{1} \leq 20 \% R\right)$ or $30 \mathrm{~m}$

- smaller of $\left(20 \% R<D_{2} \leq 40 \% R\right)$ or $60 \mathrm{~m}$

- smaller of $\left(40 \% R<D_{3} \leq 60 \% R\right)$ or $90 \mathrm{~m}$

- smaller of $\left(60 \% R<D_{4} \leq 80 \% R\right)$ or $120 \mathrm{~m}$

- smaller of $\left(80 \% R<D_{5} \leq 100 \% R\right)$ or $150 \mathrm{~m}$

where $R$ is the maximum range of the 3D imaging system. A maximum of $150 \mathrm{~m}$ was selected as this was the size of many capital projects (e.g., process plants, construction sites, buildings, bridges).

Target Reflectivity (Refl.) - 5 levels:

- $\quad 0 \% \leq$ Refl. $\leq 20 \%$

- $\quad 20 \%<$ Refl. $\leq 40 \%$

- $\quad 40 \%<$ Refl. $\leq 60 \%$

- $\quad 60 \%<$ Refl. $\leq 80 \%$

- $\quad$ Refl. $>90 \%$

Angle of incidence (between the target and the line of sight from the instrument to the target) - 4 levels:

- $\quad 0^{\circ}, 20^{\circ}, 40^{\circ}, 60^{\circ}$

Azimuth angle ${ }^{1}(\theta)-4$ levels:

- $0 \leq \theta \leq A / 4$

- $\quad A / 4<\theta \leq A / 2$

- $\quad A / 2<\theta \leq(3 / 4) A$

- $\quad(3 / 4) A<\theta \leq A$

where $\mathrm{A}$ is the horizontal field of regard ${ }^{2}$ of the $3 \mathrm{D}$ imaging system.

A total of 60 tests were suggested in the draft protocol (as opposed to 400 tests if every combination were to be tested).

1 The azimuth angle, as proposed in the ranging protocol, describes the angular range, within the instrument's horizontal field of regard (defined in Footnote 3), in which the target being measured lies

${ }^{2}$ The horizontal field of regard is the maximum angular extents (about the instrument's vertical axis - usually the $\mathrm{Z}$ axis) of an area of interest that can be measured by a 3-D imaging system as a result of scanning or reorienting the instrument's primary receiving axis
The draft protocol proposes the use of a planar target that is a minimum of $0.5 \mathrm{~m} \mathrm{x} 0.5 \mathrm{~m}$ in size. It also describes a method of processing the measurements to determine "valid" points. The calculated range to the target is then the distance from the instrument to the centroid of the valid points.

\section{PROTOCOL EVALUATION}

For the evaluation of the ranging protocol, a subset of the 60 tests was selected and two rounds of evaluation were conducted. The systems used in these evaluations would typically be used for industrial/manufacturing and construction type applications.

\subsection{First Round of Tests}

In the first round, a user performed a subset of the prescribed tests in a manufacturing facility with the participation of several members of the test methods subcommittee - ASTM E57.02.

Prior to the evaluation, target mounts and stands were fabricated and the stands were installed on the factory floor (see Figure 1). Thirteen of the 60 tests were performed.

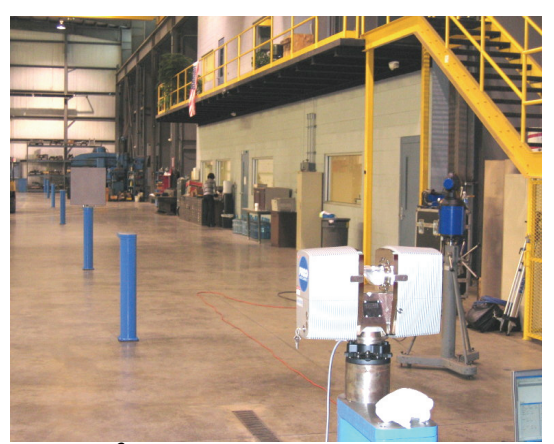

Figure $1^{3}$ Target and Target Stands

These were:

- $\quad \mathrm{AOI}=0^{\circ}$, target refl. $=20 \%, \theta=0^{\circ}$

- Distances: $7 \mathrm{~m}, 14 \mathrm{~m}, 28 \mathrm{~m}, 42 \mathrm{~m}, 70 \mathrm{~m}$

- $\mathrm{AOI}=0^{\circ}$, Distance $=28 \mathrm{~m}, \theta=0^{\circ}$

\footnotetext{
${ }^{3}$ Certain company products are identifiable in the photo. In no case does such an identification imply recommendation or endorsement by the National Institute of Standards and Technology, nor does it imply that the products are necessarily the best available for the purpose
} 
- Reflectivity $=2 \%, 20 \%, 50 \%, 75 \%, 99 \%$

- Distance $=28 \mathrm{~m}$, target refl. $=20 \%, \theta=0^{\circ}$

- $\mathrm{AOI}=0^{\circ}, 20^{\circ}, 40^{\circ}, 60^{\circ}$

The time to complete these 13 tests was approximately $8 \mathrm{~h}$. with 4 people.

Some of the challenges encountered in performing the range protocol evaluation included:

- $\quad$ Selecting a representative subset of the tests for example, instead of testing all target reflectivity values at all distances, test all reflectivity values at one distance. The question which then arose was which distance to choose: a distance closer to the instrument so that the effects of distance are minimized to reduce interaction between the two factors (distance and reflectivity) or a distance farther from the instrument to determine the "worst" condition? This leads back to the fundamental issue of the purpose of the test. Is the purpose to give the user an indication of how the instrument performs under various conditions or is it to determine if the instrument meets manufacturer specifications? Generally, more tests would be required in the former case than in the latter. In the latter case, only potential worst-case scenario tests would be specified

- Determining the perpendicularity of the planar target with respect to the instrument. Target perpendicularity was estimated by sampling 9 points on the target plane with a laser tracker. Since the 3D imaging system and the laser tracker did not have a common reference frame, the measurement was approximate, and was a cause for concern.

- Determining ground truth measurements. Since it was not possible to position the 3D imaging instrument over a known location point, the range protocol could only evaluate the relative range error.

- Determining the sequence of tests to minimize set-up time. For example, a laser tracker was used for ground truth measurements. The maximum range of the laser tracker was less than $72 \mathrm{~m}$ (the maximum test range). Therefore, the tracker had to be re-positioned for ground truth measurements at the longer distances. It was thus easier to complete all the tests at the shorter ranges first and then move the laser and complete all the tests at the longer distances.

- Processing the data. In particular, a transparent method for removing outliers and segmenting target points has to be agreed upon.

- Targets. The targets were cumbersome to work with as they were $0.6 \mathrm{~m} \times 0.6 \mathrm{~m}$, weighed about $11 \mathrm{~kg}$, and had to be handled with care to avoid contaminating the target with oils and dirt. Mounting the targets on each platform was an additional cause for delay, which would likely be eliminated through the use of standard targets and mounts.

\subsection{Second Round of Tests}

\subsubsection{Ranging protocol - planar targets}

The second round of tests was conducted at NIST and a reduction in the number of tests was achieved through a $4^{4-2}$ fractional factorial experimental design (4 factors, 4 levels) ${ }^{4}$ [2]. This experimental design reduced the number of tests from 60 to 16 and still enabled the estimation of the main factor effects. This design assumes there are no interactions between the main factors. The matrix of the 16 tests showing the various combinations is shown in Table 1.

The maximum range of the $3 \mathrm{D}$ imaging system used for these tests is greater than $100 \mathrm{~m}$. However, since the maximum range achievable in the indoor space available was $100 \mathrm{~m}$, the maximum range in these tests was set at $100 \mathrm{~m}$. Again, since these initial tests were not meant to evaluate a particular instrument but rather the range protocol itself, this deviation from the protocol was considered acceptable.

The 3D imaging system used could be centered over a known location and this allowed evaluation of the absolute as well as relative distances.

A total station was used to measure ground truth true distances. The total station and the 3D imaging system were placed at opposite ends of the $100 \mathrm{~m}$ test range with the target in between. An SMR (spherically mounted retroreflector) was

\footnotetext{
${ }^{4}$ This design is geometrically equivalent to the $4 \times 4$ Graeco-Latin Square
} 
placed over a point on the floor and was set to the same height as the total station. The distance from the total station to the SMR was measured. The 3D imaging system was then placed over the same point, and the height to the center of instrument was set to that of the total station. An estimate of the uncertainty of the true distances is $\pm 4 \mathrm{~mm}$ based on variability of the target width, total station uncertainty, the ability to center the total station over a point, and determining which point on the target to use to get ground truth.

Table 1 Second Round, Planar Target Test Matrix

\begin{tabular}{|c|c|c|c|c|}
\hline $\begin{array}{c}\text { Test } \\
\text { No. }\end{array}$ & $\begin{array}{c}\text { Dist. } \\
(\mathbf{m})\end{array}$ & $\begin{array}{c}\text { Refl. } \\
(\mathbf{\%})\end{array}$ & $\begin{array}{c}\text { AOI } \\
(\mathbf{o})\end{array}$ & $\begin{array}{c}\boldsymbol{\theta} \\
(\mathbf{o})\end{array}$ \\
\hline 1 & 10 & 2 & 0 & 30 \\
\hline 2 & 10 & 20 & 15 & 120 \\
\hline 3 & 10 & 45 & 30 & 240 \\
\hline 4 & 10 & 99 & 60 & 330 \\
\hline 5 & 40 & 2 & 15 & 240 \\
\hline 6 & 40 & 20 & 0 & 330 \\
\hline 7 & 40 & 45 & 60 & 30 \\
\hline 8 & 40 & 99 & 30 & 120 \\
\hline 9 & 70 & 2 & 45 & 330 \\
\hline 10 & 70 & 20 & 60 & 240 \\
\hline 11 & 70 & 45 & 0 & 120 \\
\hline 12 & 70 & 99 & 15 & 30 \\
\hline 13 & 100 & 2 & 60 & 120 \\
\hline 14 & 100 & 20 & 30 & 30 \\
\hline 15 & 100 & 45 & 15 & 330 \\
\hline 16 & 100 & 99 & 0 & 240 \\
\hline
\end{tabular}

The general procedure was to move the target to the approximate location, level the target both horizontally and vertically and set the height of the center of the target to same height as the center of the $3 \mathrm{D}$ imaging system. The target was then visually set (see Figure 2 ) to an approximate AOI of $0^{\circ}$. The target stand had gradations from $0^{\circ}$ to $360^{\circ}$ and the initial value corresponding to $0^{\circ} \mathrm{AOI}$ was noted. The total station measured distances to the four retrotreflectors mounted on the back of the target. The target was then rotated to the required AOI and the target was scanned once.

To calculate the distance to the target, the points in the center of the target (approximately $25 \%$ of the total target points per the protocol) were visually selected as the initial valid points (Figure 3 ). A plane was fit through these points and points with distances from the plane greater than one standard deviation were removed. The centroid of the remaining points was calculated, and the calculated range is the distance from the scanner to the centroid. (Currently, this process is performed manually but it can be automated.)

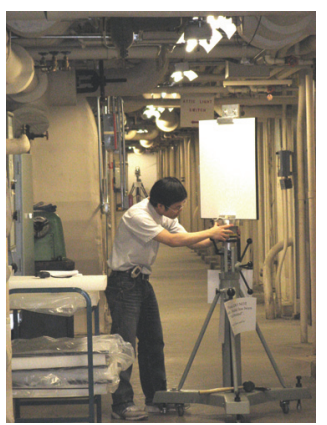

Figure 2 Target Adjustments

Preliminary results showing main factors effects are shown in Figure 4. The uncertainty of the measurements in Figure 4 is conservatively estimated as $\pm 5 \mathrm{~mm}$. From these figures, the trends in the main factor effects are discernible. The total time to conduct the 16 tests with three people, including set-up, was about $7 \mathrm{~h}$.

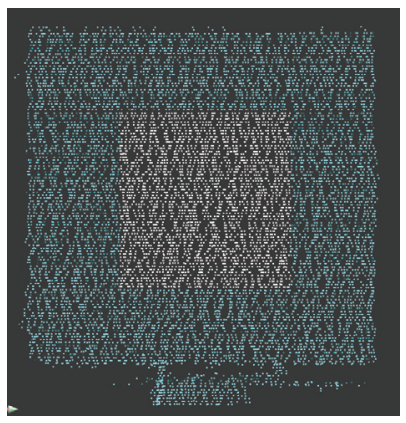

Figure 3 Selected Points in the Center of the Target Blue Points $=$ Point Cloud of Target and Mount White Points $=$ Selected Target Center Points.

The process to isolate the target points and to select the points in the center was done in about 2 h. The time to process the total station data to determine the "true" distances took about $8 \mathrm{~h}$. This included plane fits to determine the target plane, the normal to the target plane, and calculate the angle of incidence of the target plane. 


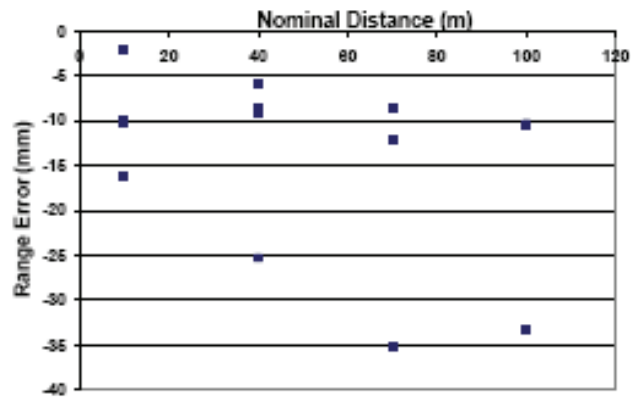

a. Effect of distance.

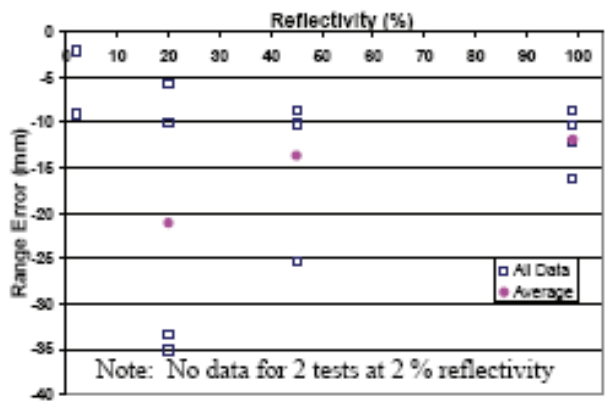

b. Effect of target reflectivity.

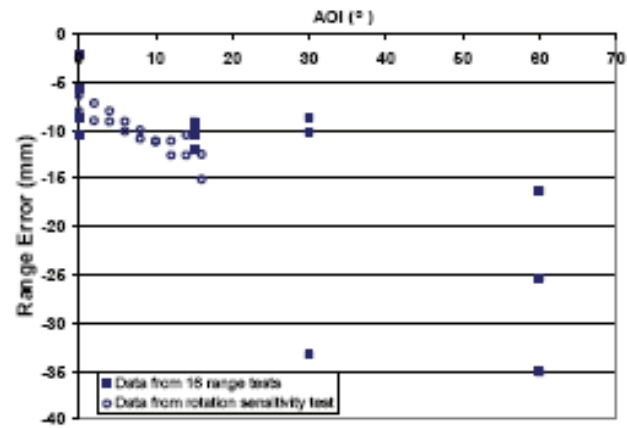

c. Effect of angle of incidence.

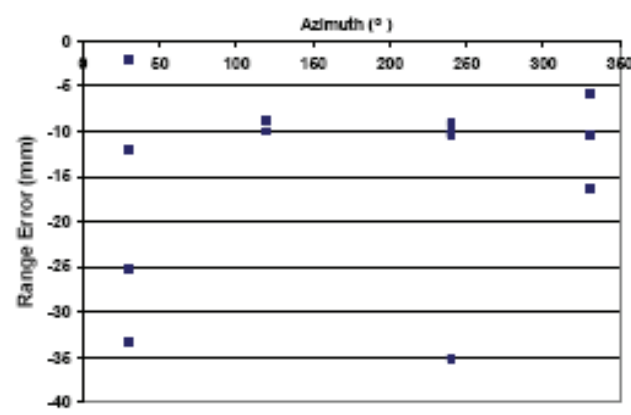

d. Effect of azimuth angle.

Figure 4 Main Factor Effects

\subsubsection{Effect of selecting off center points}

To determine the effect of using points that were not centered on the target, a short exercise was conducted. Points in the center, upper left, upper right, lower left, lower right quadrants of the target were selected. For each of these point sets, the previously described procedure to determine the centroids of these sets was used. The calculated ranges ${ }^{5}$ from the scanner to these centroids are shown in Table 2. A comparison of the results for the four quadrants with the center value shows that the calculated ranges only varied by $1 \mathrm{~mm}$ to $2 \mathrm{~mm}$ - within the noise of these instruments. Obviously, the errors will be greater as the AOI increases.

Table 2 Effects of Selection of Target Points

\begin{tabular}{|c|c|c|c|}
\hline \multirow{3}{*}{ Quadrants } & \multicolumn{3}{|c|}{ Calculated Ranges $(\mathrm{m})$ at $\mathrm{AOI}=0^{\circ}$} \\
\hline & $\begin{array}{l}1^{\text {st }} \text { Round } \\
\text { of tests }\end{array}$ & $2^{\text {nd }}$ Rou & of tests \\
\hline & $\begin{array}{c}\text { Nominal } \\
\text { range }= \\
28 \mathrm{~m}\end{array}$ & $\begin{array}{c}\text { Nominal } \\
\text { range }= \\
10 \mathrm{~m}\end{array}$ & $\begin{array}{c}\text { Nominal } \\
\text { range = } \\
100 \mathrm{~m}\end{array}$ \\
\hline Upper left & $\begin{array}{l}28.0050 \pm \\
0.006\end{array}$ & $\begin{array}{l}9.9707 \pm \\
0.004\end{array}$ & $\begin{array}{l}99.9829 \\
\pm 0.002 \\
\end{array}$ \\
\hline $\begin{array}{l}\text { Lower } \\
\text { left }\end{array}$ & $\begin{array}{l}28.0053 \pm \\
0.006\end{array}$ & $\begin{array}{l}9.9710 \pm \\
0.004\end{array}$ & $\begin{array}{l}99.9831 \\
\pm 0.002\end{array}$ \\
\hline $\begin{array}{l}\text { Upper } \\
\text { right }\end{array}$ & $\begin{array}{l}28.0062 \pm \\
0.006\end{array}$ & $\begin{array}{l}9.9716 \pm \\
0.004\end{array}$ & $\begin{array}{l}99.9863 \\
\pm 0.002\end{array}$ \\
\hline $\begin{array}{l}\text { Lower } \\
\text { right }\end{array}$ & $\begin{array}{l}28.0063 \pm \\
0.006\end{array}$ & $\begin{array}{l}9.9713 \pm \\
0.004\end{array}$ & $\begin{array}{l}99.9853 \\
\pm 0.002 \\
\end{array}$ \\
\hline Center & $\begin{array}{l}28.0058 \pm \\
0.006\end{array}$ & $\begin{array}{l}9.9707 \pm \\
0.004\end{array}$ & $\begin{array}{l}99.9842 \\
\pm 0.002\end{array}$ \\
\hline
\end{tabular}

\subsubsection{Effect of target rotation}

When drafting the range protocol, there was a concern of how one ensures that the AOI between the target and the laser beam is indeed $0^{\circ}$ - what if the target were not set exactly to $0^{\circ}$ ? How far from $0^{\circ}$ can the target be rotated to have no significant effect on the measured range? Sensitivity tests were conducted to examine this effect.

For these tests, a $99 \%$ reflective target was located at nominal distances of $10 \mathrm{~m}$ and $90 \mathrm{~m}$ from the 3D imaging system. The target was set-up in the manner described in Section 3.2.1 - starting with

\footnotetext{
${ }^{5}$ In this paper, the uncertainty of the measured distances is set equal to one standard deviation of the plane fit of the valid target points
} 
an AOI of $0^{\circ}$. The target was scanned and then it was rotated in increments of $2^{\circ}$ up to $16^{\circ}$. The Ground truth of the range from the target to the $3 \mathrm{D}$ imaging system as well as the AOI were measured with a total station. When the target was at an AOI of $6^{\circ}$, the rotation was visually discernible. results are shown in Table 3.

Table 3 Calculated Ranges of Rotated Target

\begin{tabular}{|c|c|c|c|c|}
\hline \multirow[b]{2}{*}{$\begin{array}{c}\mathrm{AOI} \\
\left({ }^{\circ}\right)\end{array}$} & \multicolumn{2}{|c|}{$\begin{array}{l}\text { Calculated Range } \\
(\mathrm{m})\end{array}$} & \multicolumn{2}{|c|}{$\begin{array}{c}\text { Range Error }{ }^{*} \\
(\mathrm{~mm})\end{array}$} \\
\hline & $\begin{array}{c}\text { Nom. } \\
\text { range = } \\
10 \mathrm{~m}\end{array}$ & $\begin{array}{l}\text { Nom. } \\
\text { range } \\
=90 \mathrm{~m}\end{array}$ & $\begin{array}{c}\text { Nom. } \\
\text { Range } \\
= \\
10 \mathrm{~m}^{* *}\end{array}$ & $\begin{array}{l}\text { Nom. } \\
\text { Range } \\
= \\
90 \mathrm{~m}^{* * *}\end{array}$ \\
\hline 0 & $\begin{array}{l}9.9847 \\
\pm 0.001\end{array}$ & $\begin{array}{c}90.2839 \\
\pm \\
0.002 \\
\end{array}$ & -6.4 & -8.0 \\
\hline 2 & $\begin{array}{r}9.9839 \\
\pm 0.001 \\
\end{array}$ & $\begin{array}{l}90.2829 \\
\pm 0.002 \\
\end{array}$ & -7.2 & -9.0 \\
\hline 4 & $\begin{array}{r}9.9835 \\
\pm 0.001\end{array}$ & $\begin{array}{l}90.2826 \\
\pm 0.002\end{array}$ & -8.0 & -9.1 \\
\hline 6 & $\begin{array}{c}9.9814 \\
\pm 0.001\end{array}$ & $\begin{array}{l}90.2826 \\
\pm 0.002\end{array}$ & -10.1 & -9.1 \\
\hline 8 & $\begin{array}{r}9.9815 \\
\pm 0.001 \\
\end{array}$ & $\begin{array}{l}90.2808 \\
\pm 0.002\end{array}$ & -10.0 & -10.9 \\
\hline 10 & $\begin{array}{r}9.9803 \\
\pm 0.001 \\
\end{array}$ & $\begin{array}{l}90.2806 \\
\pm 0.002 \\
\end{array}$ & -11.2 & -11.1 \\
\hline 12 & $\begin{array}{c}9.9793 \\
\pm 0.001 \\
\end{array}$ & $\begin{array}{l}90.2804 \\
\pm 0.002\end{array}$ & -12.6 & -11.1 \\
\hline 14 & $\begin{array}{r}9.9793 \\
\pm 0.001 \\
\end{array}$ & $\begin{array}{l}90.2810 \\
\pm 0.002 \\
\end{array}$ & -12.6 & -10.5 \\
\hline 16 & $\begin{array}{r}9.9769 \\
\pm 0.001 \\
\end{array}$ & $\begin{array}{l}90.2789 \\
\pm 0.002 \\
\end{array}$ & -15.1 & -12.5 \\
\hline $\begin{array}{l}{ }^{*} \mathrm{Ra} \\
{ }^{* *} \mathrm{Ur} \\
{ }^{* * *} \mathrm{U}\end{array}$ & $\begin{array}{l}\text { Error }= \\
\text { tainty }= \\
\text { rtainty }\end{array}$ & $\begin{array}{l}\text { lculated } \\
4.1 \mathrm{~mm} \\
4.5 \mathrm{~mm}\end{array}$ & e - & range. \\
\hline
\end{tabular}

$\mathrm{Up}$ to an AOI of $6^{\circ}$, the range errors varied by a maximum of $2 \mathrm{~mm}$ from an AOI of $0^{\circ}$. As noted previously, at a rotation of $6^{\circ}$, the fact that the plane of the target was not perpendicular to the propagation path of the laser beam was discernible and can be corrected.

\subsubsection{Sphere Targets}

ASTM E57.02 is also examining the use of spherical targets instead of planar targets. The use of spheres eliminates the need to level the target and to measure the AOI. Set up of the spheres is less cumbersome due to the reduced size as compared to the planar targets. The disadvantages of using spheres are that they are likely more expensive to fabricate, spheres with diameters of $300 \mathrm{~mm}$ or larger are needed at the longer distances, and a method of determining angle of incidence effects will have to be developed.

Only four of the 16 tests were conducted using spheres as only spheres with one reflectivity (spheres were anodized aluminum of unknown reflectivity - not critical for this protocol evaluation) were available and the AOI tests were not applicable. The four tests involved setting the spheres at four ranges at any azimuth angle and scanning them. The spheres used were not full spheres but rather $152 \mathrm{~mm}$ (6 in) diameter SMRs as shown in Figure 5. The general procedure was to center the sphere at the required nominal range and to set the height and horizontal position of the SMR so that its center was approximately along the line of sight between the total station and the 3D imaging system. A measurement from the total station to the SMR was made and then the sphere was scanned. The time to conduct the four tests was about $1.75 \mathrm{~h}$. The time to clean the point cloud and perform sphere fits was about $2 \mathrm{~h}$.

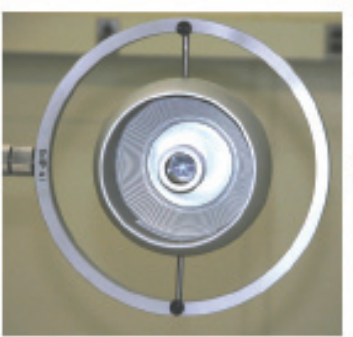

a. SMR side

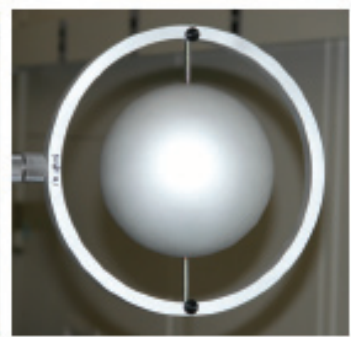

b. Sphere side
Figure 5152 mm Diameter SMRs

\section{FINDINGS AND FUTURE WORK}

Some preliminary findings from the evaluation of the ranging protocol are:

- The reduction of tests from 60 as required in the draft ranging protocol to 16 appears to be a feasible alternative. These tests can be conducted in a day and the main factor effects can be evaluated.

- Methods of determining ground truth measurements need to be clearly defined in the protocol. The uncertainty of the true 
- ranges were conservatively estimated as $\pm 4 \mathrm{~mm}$ using the total station in the second round of tests. This is about on the same order as some of the 3D imaging systems currently available. As the technology for these systems advance, it is anticipated that the range uncertainties for 3D imaging systems will reduce.

- Sphere targets were easier to use than planar targets. However, the disadvantages listed in Section 3.2.2 have to be considered.

- The effect on the calculated ranges is on the order of $2 \mathrm{~mm}$ for initial target rotations of $6^{\circ}$ or less.

- The effect on the calculated ranges is on the order of $2 \mathrm{~mm}$ for the selection of points that are off center.

One of the assumptions for the experimental design used to reduce the number of tests from 60 to 16 was that there were no interactions between the main factors. Future work needs to be performed to determine if this is indeed the case.

\section{ACKNOWLEDGMENTS}

The authors would like to express their appreciation to the following individuals who were involved with the evaluation of the ranging protocol: David Ober of Metris, Michael Garvey and Jeff Cunningham of M-7 Technologies, Fred Persi and Darin Ingimarson of Quantapoint, and Pingbo Tang, $\mathrm{PhD}$ candidate at Carnegie Mellon University. The assistance of James Yen of NIST in developing the experimental design is also much appreciated.

\section{REFERENCES}

[1] Cheok, G. S., ed. (2006), "Proceedings of the 3rd NIST Workshop on Performance Evaluation of 3D Imaging Systems," NISTIR 7357, National Institute of Standards and Technology, Gaithersburg, MD, October.

[2] Box, G. E. P., Hunter, W. G., and Hunter, J. S (1978), Statistics for Experimenters, John Wiley and Sons, New York. 